\title{
The International Code of Marketing of Breast-milk Substitutes: lessons learned and implications for the regulation of marketing of foods and beverages to children
}

\author{
Chessa K Lutter* \\ Pan American Health Organization/World Health Organization, 525 23rd Street NW, Washington, DC \\ 20037-2895, USA
}

Submitted 10 November 2011: Final revision received 10 May 2012: Accepted 4 July 2012: First published online 4 0ctober 2012

\begin{abstract}
Objective: To identify lessons learned from 30 years of implementing the International Code of Marketing of Breast-milk Substitutes ('the Code') and identify lessons learned for the regulation of marketing foods and beverages to children.

Design: Historical analysis of 30 years of implementing the Code.

Setting: Latin America and the Caribbean.

Subjects: None.

Results: Legislation to restrict marketing of breast-milk substitutes is necessary but not sufficient; equally important are the promulgation of implementing regulations, effective enforcement and public monitoring of compliance. A system of funding for regular monitoring of compliance with legislation should be explicitly developed and funded from the beginning. Economic sanctions, while important, are likely to be less effective than reports that affect a company's public image negatively. Non-governmental organizations play a critical role in leveraging public opinion and galvanizing consumer pressure to ensure that governments adopt regulations and companies adhere to them. Continual clinical, epidemiological and policy research showing the link between marketing and health outcomes and between policy and better health is essential.

Conclusions: Implementation of the Code has not come easily as it places the interests of underfinanced national governments and international and non-governmental organizations promoting breast-feeding against those of multinational corporations that make hundreds of millions of dollars annually marketing infant formulas. Efforts to protect, promote and support breast-feeding have been successful with indicators of breast-feeding practices increasing globally. The lessons learned can inform current efforts to regulate the marketing of foods and beverages to children.
\end{abstract}

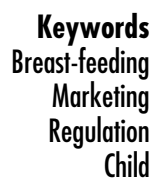

International concern about links between the marketing to children of foods high in fat and sugar and the increasing prevalence of overweight in children ${ }^{(1)}$ echoes concerns about the negative consequences of marketing breast-milk substitutes on child mortality ${ }^{(2,3)}$. While experts have drawn parallels between efforts to restrict marketing of foods and beverages to children and those of tobacco control $^{(4)}$, the author is unaware of similar research comparing restrictions on marketing of foods and beverages to children with regulation on marketing of breast-milk substitutes. Thirty years of experience implementing the International Code of Marketing of Breast-milk Substitutes ('the Code') (5) provides lessons for strategy and policy that are likely to be relevant to such regulations. The objective of the current paper is to summarize lessons learned from Code implementation and identify similarities and differences with respect to the marketing of foods and beverages to children.

\section{Methods}

The methods consist of a historical analysis of implementing and monitoring the Code. Lessons learned were drawn, in part, from a recent report summarizing 30 years of implementation of the Code in Latin America ${ }^{(6)}$. 


\section{Results}

\section{The International Code of Marketing of Breast-milk Substitutes}

The links among the marketing of breast-milk substitutes, declining rates of breast-feeding and malnutrition, morbidity and mortality were first proposed in 1939 in a presentation entitled 'Milk and murder' ${ }^{\text {(7) }}$. In 1972 Jelliffe coined the term 'commerciogenic malnutrition' (8) and in 1974 a book entitled The Baby Killer highlighted the inappropriate marketing of infant formula in Africa ${ }^{(9)}$. In 1978 the US Senate held a hearing on the advertising and promotion of infant formula in developing countries, inviting chief executive officers of multinational companies to testify ${ }^{(10)}$. The WHO held a first ever meeting on infant and young child feeding in 1979 with 150 representatives of governments, non-governmental organizations (NGO), academics and the infant food industry ${ }^{(3)}$.

In 1981, these events pushed the World Health Assembly (WHA) to adopt an International Code of Marketing of Breast-milk Substitutes ${ }^{(5)}$. The Code aimed to restrict direct promotion to the public and other practices deemed to be detrimental to public health and provide guidelines for the marketing of breast-milk substitutes, bottles and teats. The WHA has subsequently passed a number of resolutions, including as recently as 2010, aimed at closing loopholes and strengthening the guidelines ${ }^{(11)}$. Although many governments have passed legislation containing all or some of the relevant aspects of the Code, many of these have not passed regulations to implement this legislation ${ }^{(6)}$. For the most part, rigorous monitoring of compliance has not been institutionalized nor have sanctions for violators been routinely applied, despite documentation that they persist ${ }^{(12,13)}$.

The Code is only one of several policy efforts to protect, promote and support breast-feeding. The WHO and UNICEF spearheaded the 1990 Innocenti Declaration, endorsed by the 45th WHA, which set four operational targets. In 1991, the WHO and UNICEF launched the Baby Friendly Hospital Initiative to promote hospital environments conducive to breast-feeding. Many international donors supported capacity development for health workers in lactation management and counselling skills, and communications campaigns.

Disentangling the impact of policies on trends in breast-feeding is challenging because the analysis of such a relationship does not lend itself to traditional epidemiological models. None the less, the implementation of policies coincided with marked improvements in the proportion of infants exclusively breast-fed for the first 6 months of life and the median duration of breastfeeding ${ }^{(14)}$. Countries with particularly strong breastfeeding programmes include Ghana, where exclusive breast-feeding among infants less than 6 months of age increased from approximately $6 \cdot 3 \%$ in $1993^{(15)}$ to $62 \cdot 8 \%$ in $2008^{(16)}$, and Colombia, where exclusive breast-feeding increased from $11 \cdot 9 \%$ in $1990^{(17)}$ to $42 \cdot 8 \%$ in $2010^{(18)}$.

\section{Research and policies on the marketing of foods and beverages to children}

Research showing a negative association between marketing of foods and beverages to children and increased consumption has been established through empirical research, the findings of which have been confirmed by systematic reviews ${ }^{(19)}$. Children's food preferences, purchase requests and consumption patterns are influenced by advertising ${ }^{(20)}$. These results should not be surprising. Marketing works. Otherwise companies would not spend hundreds of millions of dollars advertising their products ${ }^{(21)}$. None the less, data to predict possible impacts of regulations to restrict marketing are scarce ${ }^{(22)}$. Four micro-simulation studies have modelled the hypothetical effect of restricting food marketing to children. One carried out in Québec predicted that the ban of marketing would significantly decrease the probability of purchasing fast foods ${ }^{(23)}$. Two studies were carried out in the USA, with one predicting that a complete ban of television advertising would reduce the number of overweight children and adolescents by $18 \%$ and $14 \%$, respectively ${ }^{(24)}$. The second predicted that no exposure to food advertising would lower the prevalence of obesity from $17 \cdot 8$ to $15 \cdot 2 \%{ }^{(25)}$. The last study in Australia predicted that removing the advertising of foods high in fat, sugar and salt would result in a median reduction in BMI among children of $0 \cdot 17 \mathrm{~kg} / \mathrm{m}^{2(26)}$.

The WHA, through resolution WHA63.14, endorsed a set of recommendations on the marketing of foods and non-alcoholic beverages to children in $2010^{(1)}$. They were developed with substantial input from Member States, NGO, the private sector and other stakeholders. The recommendations are intended to guide the design of new policies or strengthen existing policies on food marketing communications to children so as to reduce the marketing impact of foods high in saturated fats, trans-fatty acids, free sugars or salt. Resolution WHA63.14 requested that the Director-General provide technical support to Member States in the implementation, as well as the monitoring and evaluation, of the recommendations. More recently, the WHO issued a framework for implementation of this set of recommendations ${ }^{(27)}$.

Globally, policies on the marketing of foods and beverages to children take three forms: (i) statutory regulation, (ii) food industry pledges and (iii) self-regulatory guidelines by the advertising industry. The status of these was summarized in 2011 by Hawkes and Lobstein ${ }^{(28)}$. They report that twenty-six governments have explicit statements on marketing of food to children in strategy documents; twenty are developing or have implemented statutory measures, guidelines or approved forms of self-regulation; and four have statutory regulations specific to food. With respect to food industry pledges, between 2005 and 2009 thirteen pledges involving fifty-one 
companies were developed of which two are global, two regional and nine country-specific. Six additional pledges were published in 2010-2011, adding up to a total of nineteen. The advertising sector has also developed selfregulatory guidelines that include marketing of food to children.

\section{Similarities in the marketing of breast-milk substitutes and foods and beverages to children}

The WHA adopted both the Code and the Set of Recommendations on the Marketing of Foods and Non-alcoholic Beverages to Children in the form of a recommendation, which is not binding and thus dependent on individual Member States to design new and/or strengthen existing legislation for enforcement. The constitution of the WHO gives the WHA the power to adopt conventions, regulations and recommendations. A convention, requiring a two-thirds majority, creates a binding relationship between participating nations and international organizations and operates under the principles of international law, coming into force when ratified in accordance with the Member State's constitutional process. To date, the only such convention is the Framework Convention on Tobacco Control ${ }^{(29)}$. A regulation only requires a majority of Member States that are present for adoption and comes into force for all Members, except for those that reject the regulation or express reservations within a specified time period. A WHA recommendation to Member States has no binding authority. None the less, because it expresses the judgement of the collective membership of the highest international body in health, it carries substantial moral and political weight.

The baby food and food and beverage industries are large and powerful, with their products generating enormous profits. According to recent market research, by 2014 the global baby food market is expected to be worth \$US 37.6 billion ${ }^{(30)}$. Second quarter 2011 earnings for McDonalds, PepsiCo and Coca-Cola were \$US 6.9 billion, \$US 1.9 billion and \$US 2.8 billion, respectively ${ }^{(31)}$. These earnings represent large increases from the previous year largely because of increased sales in emerging markets. While not specific to children, they illustrate the enormity of the overall market.

The advertising budgets of both the baby food industry and the industry that markets foods and beverages to children swamp budgets for promoting healthy behaviours. In 2009, the fast-food industry spent about $16 \%$ of its annual advertising budget of \$US $4 \cdot 2$ billion on marketing to children and teenagers ${ }^{(32)}$. More than half of that amount was spent on toy giveaways and a third on television advertising. Current data on the budgets for marketing of infant formula could not be identified; the last known research quantifying such budgets was in $1973^{(33)}$. The budget for promoting breast-feeding in Latin America has been declining ${ }^{(14)}$.
Improvements in social welfare in the form of improved health are difficult to reconcile with the aims of industries that market baby foods and foods and beverages to children. Therefore, appeals to corporate social responsibility and industry self-regulation are likely to be ineffective because they expect companies to act voluntarily against shareholder interests, which they have a fiduciary responsibility to uphold ${ }^{(34)}$. As noted, 'Pleas for corporate social responsibility will only be truly embraced only by those executives who are smart enough to see that doing the right thing is a byproduct of their pursuit of profit. And that renders such pleas pointless, ${ }^{(35)}$.

\section{Differences in the marketing of breast-milk substitutes and foods and beverages to children}

There are also some important differences in the marketing of breast-milk substitutes and foods and beverages to children. The magnitude of harm from not breast-feeding is causal, immediate and well documented. Child morbidity and mortality are increased in both developed and developing countries ${ }^{(36,37)}$. The annual cost of suboptimal breast-feeding practices in the USA alone has been estimated to be \$US 13 billion $^{(38)}$. In contrast, the aetiology of childhood overweight and obesity is multifaceted with the intake of foods high in fat and sugar among many other causal factors. The health impacts do not tend to be immediate, but are often not manifest until adolescence or later, making attribution and degree of effect difficult to establish. Also, unlike the risks inherent to using infant formula ${ }^{(39)}$, not all foods and beverages are harmful to children. Therefore, it is necessary to have clear definitions of the nutritional content of foods and beverages that could be subject to regulations or exempt from them as outlined in the recent recommendations by the Pan American Health Organization $^{(22)}$.

Compared with breast-milk substitutes the market of foods and beverages aimed at children is larger, both in terms of the age range during which marketing occurs and the variety of products available. The age range for breast-milk substitutes is generally restricted to the first 2 years of life, whereas marketing of foods to children starts young and continues through adolescence. The range of products, including snacks, fast-food meals and beverages, is larger. This implies greater sales and potential losses because of marketing restrictions.

The companies with a vested interest in marketing food and beverages to children are more numerous and economically powerful than those for breast-milk substitutes. Of the five largest US companies, the largest having a revenue of $\$$ US 44.3 billion in $2009^{(40)}$, only one produces breast-milk substitutes. Of the largest ten global food companies ${ }^{(41)}$, only two produce breast-milk substitutes although the top company is a formula producer, while six produce foods and beverages advertised to children. None the less, at present it is not 
possible to make connections between company size, marketing of foods and beverages to children and child health outcomes.

\section{Lessons learned in 30 years of Code implementation relevant to marketing of foods and beverages to children}

Thirty years of implementing the Code has provided a number of lessons learned with respect to both strategy and policy, many of which are likely to be relevant for efforts to regulate the marketing of foods and beverages to children.

- Legislation to restrict marketing is necessary but not sufficient; equally important is that laws are regulated, monitored and enforced. A monitoring office, included in the original draft of the Code, was removed. Rather the Code states that monitoring should be by 'governments acting individually and collectively through the $\mathrm{WHO}^{\text {(5) }}$. In Latin America, although sixteen countries have legislation giving effect to all or some aspects of the Code, only five have regulations to enforce this legislation $^{(6)}$. With several important exceptions, enforcement has also been weak. Although many countries periodically monitor compliance with the Code, only six have ever applied sanctions. Furthermore, most reports of Code monitoring end up in the grey literature with few ever being published in peer-reviewed journals with broad circulation. Therefore, industry guidelines and/or legislation to restrict marketing of foods and beverages to children should include an independent system for regular monitoring of compliance that should be explicitly developed and funded from the beginning. To be effective, monitoring must be transparent, scientifically valid and adequately funded.

- Economic sanctions, while important, may be less effective than reports that affect a company's public image negatively. Public embarrassment on socially questionable behaviour imposes a high cost to companies. Therefore, publication of results of well-designed monitoring evaluations of industry guidelines and/or legislation to restrict marketing of foods and beverages to children in well-respected peer-reviewed journals and reported on by the media is likely to be critical for motivating compliance.

- Civil society in the form of NGO plays a critical role in leveraging public opinion and galvanizing consumer pressure to ensure that governments adopt the Code and that companies adhere to $\mathrm{it}^{(42)}$. Therefore, such groups have a large role to play in mobilizing public opinion around unrestricted marketing of foods and beverages to children and advocating for reform and national legislation. Key NGO that have commented on the WHO Set of Recommended Actions on the Marketing of Foods and Non-Alcoholic Beverages to Children ${ }^{(1)}$ and advocated on the issue include Consumers International, Corporate Accountability
International, International Association for the Study of Obesity/International Obesity Task Force, International Association of Consumer Food Organizations, International Baby-Food Action Network, International Diabetes Federation, International Pediatric Association, International Union Against Cancer and World Heart Federation, among others ${ }^{(43)}$.

- Continual clinical, epidemiological and policy research showing the link between marketing and breast-feeding practices, breast-feeding and improved maternal and child health, and breast-feeding policies (including the Code) and practices has been essential to advocate for policy reforms and to inform consumers ${ }^{(14,44)}$. Similar research also is essential for the marketing of foods and beverages in children, in order to: (i) build the evidence on its extent; (ii) establish its effects on children's food preferences, behaviours and health; and (iii) demonstrate its effects on food preferences, behaviours and health.

- Legislation to restrict marketing of breast-milk substitutes is just one of many strategies needed to protect, promote and support breast-feeding. Also important have been other strategies and initiatives to improve breast-feeding environments, legislation to improve the conditions of working women, training to improve health worker knowledge and counselling skills, and communications campaigns. Likewise, regulation of marketing of foods and beverages to children is only one piece, albeit an important one, of strategies needed to combat overweight, obesity and poor health in children. Also relevant is improving physical activity, school meals and consumption of fruits and vegetables, among other actions.

\section{Discussion}

The implementation of the Code has not come easily as it places underfinanced national governments, international and non-governmental organizations promoting breastfeeding against the interests of multinational corporations that make hundreds of millions of dollars annually marketing breast-milk substitutes ${ }^{(42,45)}$. Adequate funding to support Code implementation and other interventions has been a continuing issue as breast-feeding promotion has faded from the international health agenda ${ }^{(14)}$. None the less, efforts to protect, promote and support breast-feeding have been successful with key indicators increasing globally $^{(46)}$. The lessons from these experiences can inform current efforts to regulate the marketing of foods and beverages to children.

The effort to restrict marketing of foods and beverages to children has already galvanized international organizations, national governments, academicians and civil society. The recognition of the threat posed by the epidemic of chronic diseases, many attributable to poor nutrition and overweight, led to a recent high-level UN meeting of heads of state to address this pressing global 
public health issue ${ }^{(47)}$. The challenge is to transform these concerns into concrete regulations.

\section{Acknowledgements}

Source of funding: This research received no specific grant from any funding agency in the public, commercial or not-for-profit sector. Conflicts of interest: The author declares no conflict of interest.

\section{References}

1. World Health Organization (2010) Set of Recommendations on the Marketing of Foods and Non-Alcoholic Beverages to Children. Geneva: WHO.

2. Greiner T \& Latham MC (1982) The influence of infant food advertising on infant feeding practices in St. Vincent. Int J Health Services 12, 53-75.

3. World Health Organization (1979) Joint WHO/UNICEF Meeting on Infant and Young Child Feeding. Geneva: WHO.

4. Brownell KD \& Warner KE (2009) The perils of ignoring history: Big Tobacco played dirty and millions dies. How similar is Big Food? Milbank $Q \mathbf{8 7}, 259-294$.

5. World Health Organization (1981) The International Code of Marketing of Breastmilk Substitutes. Geneva: WHO.

6. Pan American Health Organization/World Health Organization (2011) 30 años del Código en América Latina: Un recorrido sobre diversas experiencias de aplicación del Código Internacional de Comercialización de Sucedáneos de la Leche Materna en la Región entre 1981 y 2011. Washington, DC: PAHO.

7. Williams CD (1939) Milk and murder. Address to the Rotary Club of Singapore.

8. Jelliffe DB (1972) Commerciogenic malnutrition? Nutr Rev 30, 199-205.

9. Muller M (1974) The Baby Killer. London: War on Want.

10. Nestle M (2002) Food Politics: How the Food Industry Influences Nutrition and Health. Berkeley and Los Angeles, CA: University of California Press.

11. World Health Organization (2010) WHA63.23 Infant and Young Child Nutrition. Geneva: WHO.

12. Aguayo VM, Ross JS, Kanon S et al. (2003) Monitoring compliance with the International Code of Marketing of Breastmilk Substitutes in West Africa: multisite crosssectional survey in Togo and Burkina Faso. BMJ 326, 1-6.

13. Taylor A (1998) Violations of the international code of marketing of breast-milk substitutes: prevalence in four countries. BMJ 316, 1117-1122.

14. Lutter CK, Chaparro CM, Grummer-Strawn LM et al. (2011) Backsliding on a key health investment in Latin America and the Caribbean: the case of breastfeeding promotion. Am J Public Health 101, 2130-2136.

15. Ghana Statistical Service \& Macro International Inc. (1994) Ghana Demographic and Health Survey 1993. Accra and Calverton, MD: Ghana Statistical Service and Macro International Inc.

16. Ghana Statistical Service, Ghana Health Service \& ICF Macro (2009) Ghana Demographic and Health Survey 2008. Accra and Calverton, MD: Ghana Statistical Service, Ghana Health Service and ICF Macro.

17. ProFamilia \& Institute for Resource Development/Macro International Inc. (1991) Encuesta de Prevalencia, Demografia y Salud 1990. Bogotá and Columbia, MD: ProFamilia and Institute for Resource Development/Macro International Inc.

18. Profamilia, Ministério de Protección Social, Bienestar Familiar \& US Agency for International Development
(2011) Encuesta Nacional de Demografía y Salud 2010. Bogotá and Washington, DC: Profamilia, Ministério de Protección Social, Bienestar Familiar and USAID.

19. Cairns G, Angus K \& Hastings G (2009) The Extent, Nature and Effects of Food Promotion to Children: A Review of the Evidence to December 2008. Geneva: WHO.

20. National Academy of Sciences, Committee on Food Marketing and the Diets of Children and Youth (2006) Food Marketing to Children and Youth: Threat or Opportunity? Washington, DC: National Academy Press.

21. Boyland EJ, Harrold JA, Kirkham TC et al. (2011) Food commercials increase preference for energy-dense foods, particularly in children who watch more television. Pediatrics 128, e93-e100.

22. Pan American Health Organization (2011) Recommendations from a Pan American Health Organization Expert Consultation on the Marketing of Food and Non-Alcoholic Beverages to Children in the Americas. Washington, DC: PAHO.

23. Kent MP, Dubois L \& Wanless A (2011) Food marketing on children's television in two different policy environments. Int J Pediatr Obes 6, e433-e441.

24. Chou SY, Rashad I \& Grossman M (2008) Fast-food restaurant advertising on television and its influence on childhood obesity. J Law Econ 51, 599-618.

25. Veerman JL, Van Beeck EF, Barendregt JJ et al. (2009) How much would limiting TV food advertising reduce childhood obesity? Eur J Public Health 19, 365-369.

26. Magnus A, Haby MM, Carter R et al. (2009) The costeffectiveness of removing television advertising of high-fat and/or high-sugar food and beverages to Australian children. Int J Obes (Lond) 33, 1094-1102.

27. World Health Organization (2012) Framework for Implementing the Set of Recommendations on the Marketing of Foods and Non-alcoholic Beverages to Children. Geneva: WHO.

28. Hawkes C \& Lobstein T (2010) Regulating the commercial promotion of food to children: a survey of actions worldwide. Int J Pediatr Obes 6, 83-94.

29. World Health Organization (2003) WHO Framework Convention on Tobacco Control. Geneva: WHO.

30. MarketsandMarkets (2009) Global Baby Food Market (2009-2014). Dallas, TX: MarketsandMarkets.

31. Nestle M (2011) Where are junk-food companies making money? Emerging markets. http://www.theatlantic.com/ life/archive/2011/07/where-are-junk-food-companies-makingmoney-emerging-markets/242627/ (accessed October 2011).

32. Harris JL, Schwartz MB \& Brownell KD (2010) Fast Food FACTS: Evaluating Fast Food Nutrition and Marketing to Youth. New Haven, CT: Yale Rudd Center for Food Policy and Obesity.

33. Greiner $\mathrm{T}$ (1975) The Promotion of Bottle Feeding by Multinational Corporations: How Advertising and the Health Profession Have Contributed. Cornell International Nutrition Monograph Series no. 2. Ithaca, NY: Cornell University

34. Gilmore AB, Savell E \& Collin J (2011) Public health, corporations and the New Responsibility Deal: promoting partnerships with vectors of disease? J Public Health 33, 2-4.

35. Karnani A (2010) The case against corporate social responsibility. Wall Street Journal, 23 August; available at http://online.wsj.com/article/SB100014240527487033380045 $75230112664504890 . \mathrm{html}$

36. Ip S, Chung M, Raman G et al. (2007) Breastfeeding and maternal and infant health outcomes in developed countries. Evid Rep Technol Assess (Full Rep) issue 153, 1-186.

37. WHO Collaborative Study Team (2000) The role of breastfeeding on the prevention of child mortality due to infectious diseases in developing countries: a pooled analysis. Lancet 355, 451-455. 
38. Bartick M \& Reinhold A (2010) The burden of suboptimal breastfeeding in the United States: a pediatric cost analysis. Pediatrics 125, e1048-e1056.

39. Chenu JW \& Cox JM (2009) Cronobacter ('Enterobacter sakazakii'): current status and future prospects. Lett Appl Microbiol 49, 153-159.

40. Robertson K (2010) America's Biggest Food Companies. http:// www.forbes.com/sites/investopedia/2010/11/02/americasbiggest-food-companies/2/ (accessed November 2010).

41. Hunkar D (2008) The Top 10 Global Food Producers: An Overview. http://seekingalpha.com/article/102103-the-top-10global-food-producers-an-overview (accessed October 2008).

42. Allain A (2005) Fighting an Old Battle in a New World. Uppsala: International Baby Food Action Network.

43. World Health Organization (2008) Dialogue with Nongovernmental Organizations Regarding the Drafting of
Recommendations on the Marketing of Foods and NonAlcoholic Beverages to Children. Geneva: WHO.

44. Lutter CK (2000) Breastfeeding promotion: is its effectiveness supported by scientific evidence and global changes in breastfeeding behaviors? In Short and Long Term Effects of Breastfeeding on Child Health, pp. 355-368. [B Koletzko, editor]. Dordrecht: Kluwer Academic Plenum Publishers.

45. Richter J (2001) Holding Corporations Accountable. New York: St Martin's Press, LLC.

46. Lutter CK \& Morrow AL (2012) Protection, promotion and support and global trends in breastfeeding. Adv Nutr (In the Press).

47. United Nations General Assembly (2011) High-Level Meeting on Prevention and Control of Non-Communicable Diseases. New York: UN. 